\title{
Socio-economic status and health awareness are associated with choice of cooking oil in Costa Rica
}

\author{
Uriyoán Colón-Ramos ${ }^{1, *}$, Edmond K Kabagambe ${ }^{2}$, Ana Baylin ${ }^{3}$, Alberto Ascherio ${ }^{4}$, \\ Hannia Campos ${ }^{4}$ and Karen E Peterson ${ }^{4}$ \\ 'National Cancer Institute, 6130 Executive Boulevard, Bethesda, MD 20892, USA: ${ }^{2}$ Department of Epidemiology, \\ University of Alabama at Birmingham, Birmingham, AL, USA: ${ }^{3}$ Department of Community Health, Brown University, \\ Providence, RI, USA: ${ }^{4}$ Department of Nutrition, Harvard School of Public Health, Boston, MA, USA
}

Submitted 4 July 2006: Accepted 11 December 2006: First published online 29 March 2007

\begin{abstract}
Objective: To examine the socio-economic and lifestyle determinants of cooking oil choice in Costa Rica during the last decade (1994-2004).

Design: Cross-sectional study. Subjects (total $n=2274$ ) belonged to the control population of a large case-control study; they were recruited yearly. Data about type of oil used for cooking, dietary intake, socio-economic and demographic characteristics were collected.

Setting: A dietitian visited all subjects and conducted the interviews at their homes; all subjects lived in the Costa Rican central valley region.

Subjects: Adult, free-living, rural and urban Costa Ricans with no history of myocardial infarction and physical or mental disability.

Results: The odds of choosing soybean over palm oil increased significantly each year $(P<0.05)$ and was determined by high socio-economic status (SES) and variables that suggest health awareness (self-reported history of hypertension, high cholesterol, multivitamin use and intake of green leafy vegetables). The odds of choosing other unsaturated oils, namely corn and sunflower, over soybean oil also increased yearly $(P<0.05)$ and was associated with the same two factors (high SES and health awareness). Palm oil users remained in the lowest SES tertile and were more likely to live in rural areas. Across all SES tertiles, high health awareness determined the odds of choosing other unsaturated oils over palm oil, and soybean oil $(P<0.05)$.

Conclusion: These data show that, in addition to SES, health awareness is associated with the selection of unsaturated oils over palm oil in a developing country undergoing transition. These data should be considered when targeting nutrition messages and policies that promote better dietary choices.
\end{abstract}

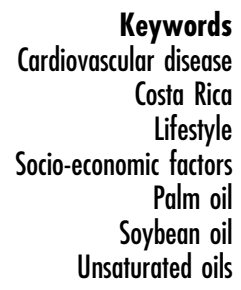

In developing countries, the major source of fat is cooking oil $^{1,2}$. The type and amount of oil consumed are important predictors of plasma lipid profiles and cardiovascular disease $^{3-6}$. Traditionally in Costa Rica, as in many other developing countries, the major source of cooking oil has been palm oil ${ }^{7}$. During the 1990s an important decrease in palm oil consumption was recorded, where Costa Rican household consumption dropped by $72 \%$ per capita; consumption of other vegetable oils, mainly soybean oil, experienced a simultaneous increase of $86 \%{ }^{8}$. Little is known about the characteristics of the consumers of each type of oil during this national shift in oil use.

As rates of mortality from ischaemic disease increase in Costa Rica and Latin America ${ }^{9-11}$, it is important to understand the determinants of cooking oil choices in order to inform nutrition policies and target messages to populations at risk. Only a few studies have examined the characteristics of people who consume different types of oils; they have shown a high consumption of palm oil among rural and poor Costa Rican populations ${ }^{12-14}$, but other factors relating to lifestyle or health awareness may also be important determinants of oil choice ${ }^{15,16}$. In the light of dietary changes in cooking oil preferences, the present study examines the socio-economic and lifestyle determinants of the choice of cooking oil during this important dietary change in cooking oil.

\section{Materials and methods}

\section{Study population}

The subjects in this paper belonged to the control population $(n=2274)$ of a large case-control study in Costa Rica, which was designed to examine the risk factors for myocardial infarction in the central valley area. 
The present analysis focuses only on the control population, and details on the overall case-control design can be found elsewhere ${ }^{17,18}$. Briefly, cases were survivors of a first acute myocardial infarction, and they were recruited each year for a period of 10 years. Similarly, control subjects were randomly selected each year, for 10 years, using information available from the National Census and Statistics Bureau of Costa Rica and were matched for age ( \pm 5 years), sex and area of residence with each case. Control subjects were ineligible if they had ever had a myocardial infarction or were physically or mentally unable to answer the questionnaires.

The control population is generally representative of the Costa Rican central valley population within matched strata. The central valley region of Costa Rica covers a full range of urban and rural lifestyles as well as socioeconomic levels. Because of the comprehensive social services provided in Costa Rica, all persons living in the catchment area had access to medical care without regard to income; therefore, the subjects for this study were randomly selected from all socio-economic levels, areas of residence and counties.

All subjects gave informed consent on documents approved by the Human Subjects Committee of the Harvard School of Public Health and the University of Costa Rica. Out of all subjects eligible to be controls, 88\% participated in the study as controls.

\section{Data collection}

Each year, control subjects were recruited to match the cases of myocardial infarction during the same study period. Therefore, the design of this study consists of successive cross-sectional data collected throughout a period of 10 years (1994-2004).

Subjects were visited at their homes for data collection. Data on income, years of formal education, number of household possessions and occupation were collected. Household income was assessed as \$US per month; a household possession index was created as a sum of values assigned for each electrical appliance (radio, television, stereo, refrigerator, etc.) with higher values being assigned to more expensive items; occupation during the previous year was coded using the Costa Rican Labor Code from the Ministry of Labor ${ }^{19}$ with lower codes assigned to professions with lower salaries. Smoking status and medical history were also collected. Self-reported diabetes and hypertension were validated using the recommended definitions by the Expert Committee on the Diagnosis and Classification of Diabetes Mellitus ${ }^{20}$ and the Third Joint National Committee on Detection, Evaluation, and Treatment of High Blood Pressure ${ }^{21}$, respectively.

Anthropometric measures were taken during home visits. Subjects were also asked about the average frequency and time spent on several occupational and leisure-time activities during the last year. Energy expenditure was calculated for each activity as the product of frequency (times per week), duration (hours per time) and intensity (metabolic equivalent task or MET). Validation studies and details are published elsewhere ${ }^{17,18}$.

Dietary intake was collected using a food-frequency questionnaire that was developed and validated specifically to assess fatty acid intake among the Costa Rican population $^{4,22,23}$. The instrument also inquired about the type of fat most frequently used for home cooking or frying; it was confirmed by visual identification at the subject's home. The fatty acid composition of all foods and oils commonly consumed in Costa Rica was assessed using the same methodology as for biological samples ${ }^{24}$. These analyses were incorporated into the nutrient database for the assessment of fatty acid intake.

\section{Statistical analysis}

Statistical Analysis Systems software version 8.00 (SAS Inc.) was used for analyses. Variables were checked for outliers and normality, and, where necessary, transformed using natural logarithm or square-root transformation. Individuals with missing values for type of oil used for cooking, physical activity, weight, height, waist circumference or income were deleted. Of the 2274 control subjects recruited over a period of 10 years (1994-2004), 1938 subjects were retained; $25 \%$ were female.

Type of cooking oil was categorised as follows: (1) palm oil shortening, main oil rich in saturated fats; (2) soybean oil, a major source of $\alpha$-linolenic and, if partially hydrogenated, trans-fatty acids; and (3) oils other than soybean that are rich in unsaturated fats (sunflower, corn and olive).

An index for socio-economic status (SES) was created by summing quintiles of income, groupings of years of education, categories of occupation and index of household possessions. The SES index was evaluated by its association with variables that were observed directly by the interviewer, such as number of cars, household construction materials for walls, ceiling and roof, phone and answering machine services, and type of potable water and sanitary services. In all cases, the index performed well.

Factors that were independent predictors of oil choice and that suggested health alertness were grouped together as a 'health awareness' variable. The following variables were included: self-reported history of hypertension and high cholesterol (yes $=1$ ), frequent multivitamin use (yes $=1$ ), non-smoking status (yes $=1$ ) and high intake of green leafy vegetables (defined as intake greater than or equal to the median intake of 0.65 servings per day) (yes $=1$ ). High health awareness was assigned if the majority (at least three out of five) of the component variables were reported as 'yes'.

Student $t$-tests and $\chi^{2}$ tests were used to determine significant differences $(P<0.05)$ in socio-economic and 
lifestyle characteristics among rural and urban residents. For analyses, control subjects were classified into three groups (1995-1997, 2000-2001, 2002-2004) according to the year in which they served as a control subject to the larger case-control study. To test for significant changes between year batches within each group of oil users, values of least squares means, adjusted for age, gender and residential area, were examined using the Tukey multiple comparisons test.

Three logistic regression models were created with the following binary response outcomes: (1) modelling the choice of soybean oil vs. palm oil (soybean $=1$ vs. palm $=0$ ); (2) modelling the choice of oils rich in unsaturated fats vs. palm oil (other unsaturated $=1$ vs. palm $=0$ ); and (3) modelling the choice of oils rich in unsaturated fats vs. soybean oil (other unsaturated $=1$ vs. soybean $=0$ ). Univariate logistic regression analyses were used to examine pre-specified variables of interest as independent predictors of the choice of cooking oil. A dummy variable for time was created for each 12-month period since 1994 until 2004. Finally, interactions with time were tested for each variable that appeared to change over time in the preliminary analyses. The final multivariate logistic regression model displays significant determinants of oil choice adjusting for all relevant variables, including age and gender. Statistical significance of interactions between SES and health awareness in oil choice was tested using the likelihood ratio test.

\section{Results}

Table 1 shows SES and lifestyle characteristics by area of residence for all subjects for the total time period of 10 years. In general, it appears that soybean oil was widely used in both areas (49 and 54\% in rural and urban areas, respectively). In rural areas, palm oil was the second most consumed oil (28\%), whereas in urban areas it was other unsaturated oils (i.e. corn, sunflower and olive) (26\%). Among other unsaturated oils, corn and sunflower oils were the most commonly used (20\%), followed by olive (2.4\%) and other oils (1\%).

Table 2 shows the general characteristics of the different cooking oil users classified into three groups (1995-1997, 2000-2001, 2002-2004) adjusted by age, gender and area of residence. Overall, palm oil users had lower SES, education level and income, and they were more likely to be unemployed or employed in agricultural or semiskilled professions $(P<0.05)$ compared with users of soybean oil and other unsaturated oils. Soybean oil users were of moderate to low SES; their level of education, income and number of household possessions were significantly higher than those of palm oil users, but lower than for the consumers of other unsaturated oils $(P<0.05)$. Consumers of other unsaturated oils had significantly more years of formal education, higher income and a larger number of household possessions than those who consumed any other type of cooking oil $(P<0.001)$.

\section{Preference in use of cooking oil throughout the years}

Figure 1 shows the frequency of use of each type of oil over time. There was a significant decrease in the use of palm oil from 1995 to 2004 (60\% reduction in percentage of users), while soybean oil and other unsaturated oils increased significantly $(P<0.001)$. This trend was apparent and significant in both rural and urban areas $(P<0.001)$ (results not shown). Interestingly, there was also a significant increasing trend $(P<0.001)$ for the use of other unsaturated oils compared with soybean oil.

Table 3 shows three multivariate logistic regressions that model different choices of oil. The variable 'year of study' was included to estimate how the determinants of choice differed every 12 months (a different group of subjects was recruited each year). An odds ratio $(\mathrm{OR})>1$ indicates that the odds of choosing one type of oil vs. another are positively influenced by that variable. Conversely, an OR $<1$ indicates that the odds of choosing one type of oil vs. another are negatively influenced by that variable. The results show a positive association between high SES and the odds of choosing soybean vs. palm oil, and other unsaturated oils vs. palm oil. The same is true for the variables history of hypertension and high cholesterol, intake of green leafy vegetables, male gender and older age. Conversely, there was a significant negative association between physical activity and choice of other unsaturated oils vs. palm oil, and other unsaturated oils vs. soybean oil. The variable 'year of study' was positively associated with oil choice in all three models.

Figure 2 shows a combined positive effect of high SES and high health awareness for the choice of soybean and other unsaturated oils vs. palm oil. High health awareness, a summary variable that grouped independent predictors of oil choice (self-reported history of hypertension and high cholesterol, multivitamin use, smoking status and intake of green leafy vegetables), also played a significant role in the choice of other unsaturated oils over soybean oil; this is apparent across all SES. This association was adjusted for gender, age, physical activity, year and area of residence.

All models were controlled for age and area of residence. The following characteristics were included in all models, but did not remain significant in the multivariate analyses: waist-to-hip ratio, body mass index (BMI), waist circumference, history of diabetes and intake of all fruits.

\section{Discussion}

This study assessed the determinants of oil choice in the larger central valley region of Costa Rica over a period of 10 years (1994-2004) using a cross-sectional design. 
Table 1 General characteristics of the study population (using the total control population of the Costa Rica Heart Disease Study, 1994-2004)

\begin{tabular}{|c|c|c|}
\hline Variable & $\begin{array}{l}\text { Rural residents } \\
\quad(n=480)\end{array}$ & $\begin{array}{l}\text { Urban residents } \\
\quad(n=1458)\end{array}$ \\
\hline Females in the population & $115(24)$ & $310(25)$ \\
\hline Age (years) ${ }^{\star}$ & $59.2 \pm 10.9$ & $57.6 \pm 11.3$ \\
\hline Weight (kg) & $70.1 \pm 13.6$ & $71.4 \pm 13.7$ \\
\hline Height $(\mathrm{cm})^{\star}$ & $163 \pm 9$ & $164 \pm 9$ \\
\hline Body mass index $\left(\mathrm{kg} \mathrm{m}^{-2}\right)$ & $26.3 \pm 4.2$ & $26.5 \pm 4.3$ \\
\hline Waist-to-hip ratio* & $0.96 \pm 0.08$ & $0.95 \pm 0.07$ \\
\hline Physical activity $(\mathrm{MET})^{\star}, \dagger$ & $1.74 \pm 0.85$ & $1.50 \pm 0.62$ \\
\hline Fasting glucose (mg/100 ml) & $83 \pm 31$ & $82 \pm 32$ \\
\hline Systolic blood pressure $(\mathrm{mmHg})^{\star}$ & $139 \pm 23$ & $136 \pm 23$ \\
\hline Diastolic blood pressure $\left(\mathrm{mmHg}^{*}\right.$ & $82 \pm 10$ & $82 \pm 11$ \\
\hline High health awareness $\ddagger$ & $124(26)$ & $440(30)$ \\
\hline \multicolumn{3}{|l|}{ Variables suggesting health awareness } \\
\hline History of hypertension§ & $138(29)$ & $437(30)$ \\
\hline History of high cholesterol§ & $120(25)$ & $113(28)$ \\
\hline Taking multivitamins & $26(5)$ & $113(8)$ \\
\hline Current smokers & $98(20)$ & $311(21)$ \\
\hline Mean cigarettes/day among current smokers $(n=409)^{\star}$ & $15.4 \pm 12.6$ & $12.8 \pm 11.3$ \\
\hline Green leafy vegetables (servings/day)* & $0.77 \pm 0.38$ & $0.81 \pm 0.38$ \\
\hline \multicolumn{3}{|l|}{ SES index } \\
\hline Average* $^{*}$ & $6.9 \pm 3.6$ & $8.7 \pm 3.7$ \\
\hline Highest tertileq & $109(23)$ & $554(39)$ \\
\hline \multicolumn{3}{|l|}{ Components of SES index } \\
\hline Formal education (years) ${ }^{\star}$ & $6.2 \pm 4.5$ & $8.3 \pm 5.6$ \\
\hline Monthly household income (\$US)* & $445 \pm 357$ & $610 \pm 436$ \\
\hline \multirow{2}{*}{\multicolumn{3}{|c|}{ Occupation*, ** }} \\
\hline & & \\
\hline Unemployed & $212(44)$ & $563(39)$ \\
\hline Semi-skilled & 175 (19) & 432 (32) \\
\hline Professional & $93(36)$ & $463(30)$ \\
\hline \multicolumn{3}{|l|}{ Choice of cooking oil†† } \\
\hline Palm & $135(28)$ & $292(20)$ \\
\hline Soybean & $234(49)$ & $788(54)$ \\
\hline Other unsaturated $\ddagger \ddagger$ & $111(23)$ & $378(26)$ \\
\hline
\end{tabular}

Data are presented as $n(\%)$ or mean \pm standard deviation.

${ }^{\star}$ Means are significantly different (Student $t$-test): $P<0.05$

† MET - metabolic equivalent task: $1 \mathrm{MET}=$ energy expenditure of sitting quietly or approximately $1 \mathrm{kcal}$ per kg body weight perh.

$¥$ Score for high health awareness was calculated as a sum of self-reported history of hypertension and high cholesterol, frequent multivitamin use, non-smoking status and high intake of green leafy vegetables ( $\geq$ median intake of 0.65 servings per day). At least three out of five components had to be classified as 'yes' $(=1)$.

$\S$ These variables are self-reported medical histories.

I Socio-economic status (SES) index was calculated as a measure of quintiles of income, formal education, number of household possessions and occupation.

\| Household possessions: sum of values assigned for each appliance in the home.

${ }^{* \star}$ Occupation: refers to occupation in the previous year. 'Unemployed' includes retired persons, housekeepers, students or unemployed; 'Semi-skilled' includes agricultural work, plumbers, drivers and others; 'Professionals' includes managers, administrators and professionals.

†† Percentages are significantly different $\left(\chi^{2}\right.$ test): $P<0.05$.

$\ddagger \ddagger$ Other unsaturated oils refer to corn and sunflower oils (used by $20 \%$ of the population), olive oil ( $2.4 \%)$ and others (1\%).

Results in this study population show a decrease in palm oil consumption paired with a simultaneous increase in the use of soybean oil and other unsaturated oils (i.e. corn, sunflower and olive oils). This is consistent with reports from the 1989, 1991 and 2001 Costa Rican National Food Surveys ${ }^{8,25}$. The odds for choosing 'other' unsaturated oils (namely corn or sunflower oil) over soybean oil increased each year. High SES and variables that suggest high health awareness were positive determinants of the choice of unsaturated oils, including soybean oil.

There are various remarkable dimensions to these differences by year of study. First, palm oil, a local Costa Rican product subsidised by the government, costs less than liquid unsaturated oils which are often imported $^{26}$ (i.e. a litre of unsaturated vegetable oil currently costs about \$US 1.30 vs. \$US 1.20 per kilo of palm oil) and palm oil can be more cost-efficient, since the same quantity can often be re-heated multiple times for frying, delivering more uses by quantity than the unsaturated counterparts. This may be more appealing to lower-income individuals; according to our observations in 2004 most palm oil users were characterised by low-income status, fewer household possessions and low-paying occupations. These findings are consistent with the results from a 1991 national survey in Costa Rica that showed a decrease in the use of palm oil and a simultaneous increase in intake of 
unsaturated vegetable oils with every increase in decile of income? .

Preference away from palm oil and toward unsaturated oils may be partly attributable to perceptions of healthfulness. Although palm oil is rich in monounsaturated fatty acids as well as tocopherols among other antioxidants, its high concentration of saturated fatty acids (36-49\%) makes this oil potentially atherogenic ${ }^{7,27}$. On the other hand, soybean, corn, sunflower and olive oils are rich in unsaturated fatty acids; in particular, soybean oil is naturally rich in heart-beneficial $\alpha$-linolenic acid $(7-10 \%)$. Congruent with this hypothesis, our findings show that variables related to heath awareness (reported history of hypertension and high cholesterol, and high intake of green leafy vegetables) were associated with choice of all unsaturated oils over palm oil.

The effects of a strong public health campaign, coupled with the marketing expertise of private industry, should not be underestimated in its capacity to modify traditional food patterns, even among low-income individuals. Even though palm oil was traditionally preferred in Costa Rica for its unique cooking attributes ${ }^{14}$, soybean oil was introduced with a strong marketing and educational campaign that touted its health benefits over palm oil. Sales of soybean oil increased by $21 \%$ after this campaign $^{28}$. In concurrence, our findings suggest that even among the lowest SES tertiles, subjects with characteristics that suggest high health awareness were more likely to choose all unsaturated oils over palm than those with low health awareness. The public health sector should tap into this resource to direct populations to healthier choices.

Interestingly, variables that suggest health awareness (reported history of hypertension, frequent multivitamin use, high intake of green leafy vegetables) were also positive determinants of the choice of other unsaturated oils (corn, sunflower or olive) vs. soybean oil. Healthaware subjects with higher risk of developing diseases have been shown to be more likely to adopt a preventive behaviour, such as a change of diet ${ }^{29}$. Subjects with a medical history may prefer other unsaturated oils to soybean perhaps because these oils are marketed and labelled as protective against cardiovascular disease. Since Costa Rica lacks its own national regulation for nutrition labelling, health claims in labels are voluntary and left to the discretion of the food industry $y^{30,31}$; the inconsistency in labelling across oil brands and types causes confusion among consumers and may ultimately benefit the sales of other unsaturated oils over soy. Furthermore, it is also possible that some subjects were actively discouraged from consuming soybean oil because, due to partial hydrogenation, the high trans-fatty acid content of this oil in Costa Rica has been associated with increased risk of myocardial infarction ${ }^{32}$. Although the trans-fat content of soybean oil decreased considerably during the period that this study was conducted ${ }^{24}$, no indication of the trans-fat 


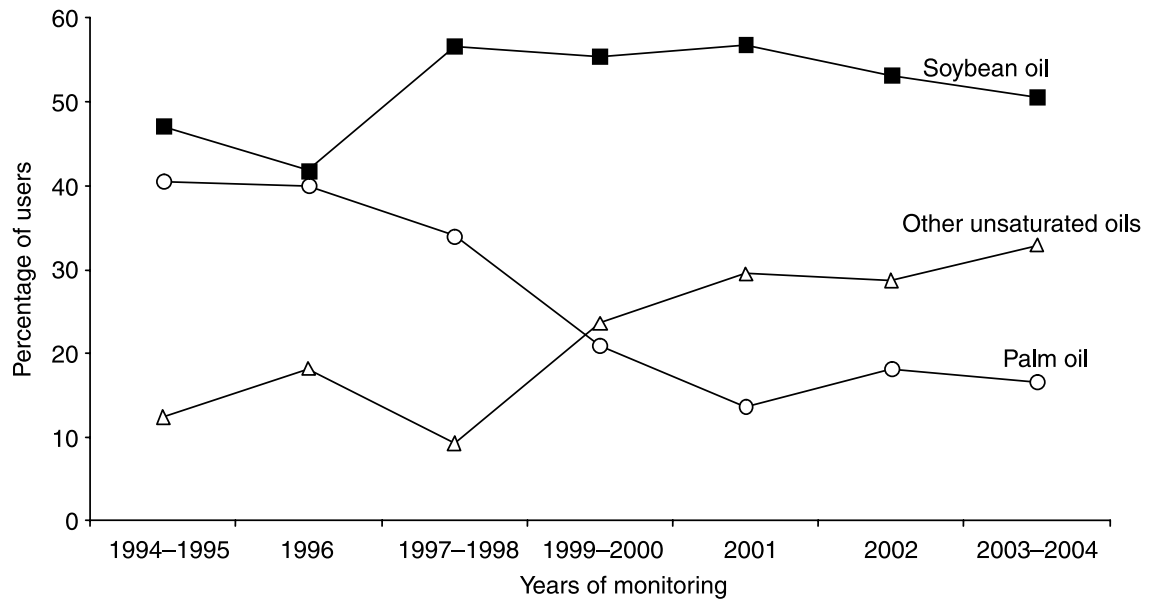

Fig. 1 Percentage of cooking oil users by type of oil, classified every 12 months approximately (using the control population of the Costa Rica Heart Disease Study, 1994-2004)

content ever appeared on its nutrition label. Despite this, correct labelling and marketing strategies should be in place to inform and orient health-aware consumers about food choices. This is especially important given that the use of other unsaturated oils is expanding and that these unsaturated oils are now available even in low-income supermarket chains ${ }^{33}$. Although the price of olive, canola and corn oils is generally higher than that of soybean oil, the price of sunflower oil is now comparable to that of soybean, potentially further expanding its use.

Physical activity in this study was analysed as the daily work-related activities, and is not necessarily reflective of sports or recreational activities related to health awareness. Low physical activity levels and high BMI among unsaturated oil users may arise because the majority of these oil users lived in urban areas. Urban sprawl has been associated with lower rates of walking and higher $\mathrm{BMI}^{34}$, and rural residents in Costa Rica have been shown to be more active, maintaining a low $\mathrm{BMI}^{12,13}$. The majority of these oil users also belonged to the highest SES, which has been associated with sedentary lifestyle in some countries ${ }^{35,36}$. Interestingly, our study showed that physical activity among unsaturated oil users increased throughout the years and was comparable, in the later years of the study, to activity levels of palm oil users. This suggests a change in behaviour patterns of urban subpopulations or high-SES groups; further analyses should examine the shifts in lifestyle patterns and trends in health and eating behaviours in Costa Rica as part of a nutrition transition investigation.

Owing to the nature of these cross-sectional data, which were obtained from a study designed with different

Table 3 Logistic regression models of the choice of cooking oil (using the control population of the Costa Rica Heart Disease Study, 1994-2004); all variables were entered in the model simultaneously

\begin{tabular}{|c|c|c|c|}
\hline \multirow[b]{2}{*}{ Variable } & \multicolumn{3}{|c|}{ Odds ratio or coefficient ( $95 \%$ confidence interval) } \\
\hline & $\begin{array}{l}\text { Soybean oil } \\
\text { vs. palm oil }(n=1410)\end{array}$ & $\begin{array}{l}\text { Other unsaturated } \\
\text { oils vs. palm oil }(n=897)\end{array}$ & $\begin{array}{l}\text { Other unsaturated } \\
\text { oils vs. soybean oil } \\
\quad(n=1467)\end{array}$ \\
\hline Year of study* (12-month increases) & $1.26(1.18,1.35) \S$ & $1.48(1.35,1.63) \S$ & $1.18(1.10,1.27) \S$ \\
\hline SES (highest vs. lowest tertile) & $4.56(3.13,6.66) \S$ & $11.86(7.20,19.35) \S$ & $2.72(1.92,3.88) \S$ \\
\hline Residence (1 = urban) & $1.42(1.07,1.88) \S$ & $1.22(0.84,1.79)$ & $0.91(0.69,1.20)$ \\
\hline Gender ( $1=$ men $)$ & $1.36(1.01,1.88) \S$ & $1.73(1.16,2.56) \S$ & $1.35(1.03,1.79) \S$ \\
\hline Age (5-year increases) $†$ & $1.08(1.02,1.15) \S$ & $1.17(1.08,1.27) \S$ & $1.11(1.10,1.18) \S$ \\
\hline Physical activity (MET) & $0.93(0.79,1.09)$ & $0.73(0.55,0.97) \S$ & $0.81(0.66,1.00) \S$ \\
\hline \multicolumn{4}{|l|}{ Variables suggesting health awareness } \\
\hline History of hypertension ( $1=$ yes $)$ & $1.07(0.79,1.44)$ & $1.51(1.05,2.20) \S$ & $1.31(1.02,1.68) \S$ \\
\hline History of high cholesterol ( $1=$ yes $)$ & $1.41(1.03,1.92) \S$ & $1.64(1.11,2.40) \S$ & $1.09(0.85,1.41)$ \\
\hline Multivitamin use ( $1=$ yes $)$ & $1.37(0.76,2.45)$ & $1.48(0.76,2.88)$ & $1.57(1.06,2.36) \S$ \\
\hline Current non-smokers $(1=$ yes $)$ & $1.25(0.93,1.66)$ & $1.20(0.79,1.81)$ & $1.16(0.85,1.59)$ \\
\hline Green leafy vegetables (servings/day)‡ & $2.45(1.74,3.46) \S$ & $4.00(2.57,6.24) \S$ & $1.49(1.09,2.03) \S$ \\
\hline
\end{tabular}

SES - socio-economic status; MET - metabolic equivalent task.

* Due to the cross-sectional nature of this study, the variable 'year of study' indicates each 12-month period in which a different group of subjects served as controls for the Costa Rica Heart Disease Project, 1994-2004.

$\dagger$ Age ranges from 35 to 75 years.

‡ Significance tests based on square-root-transformed data.

$\S$ Significantly different: $P<0.05$. 


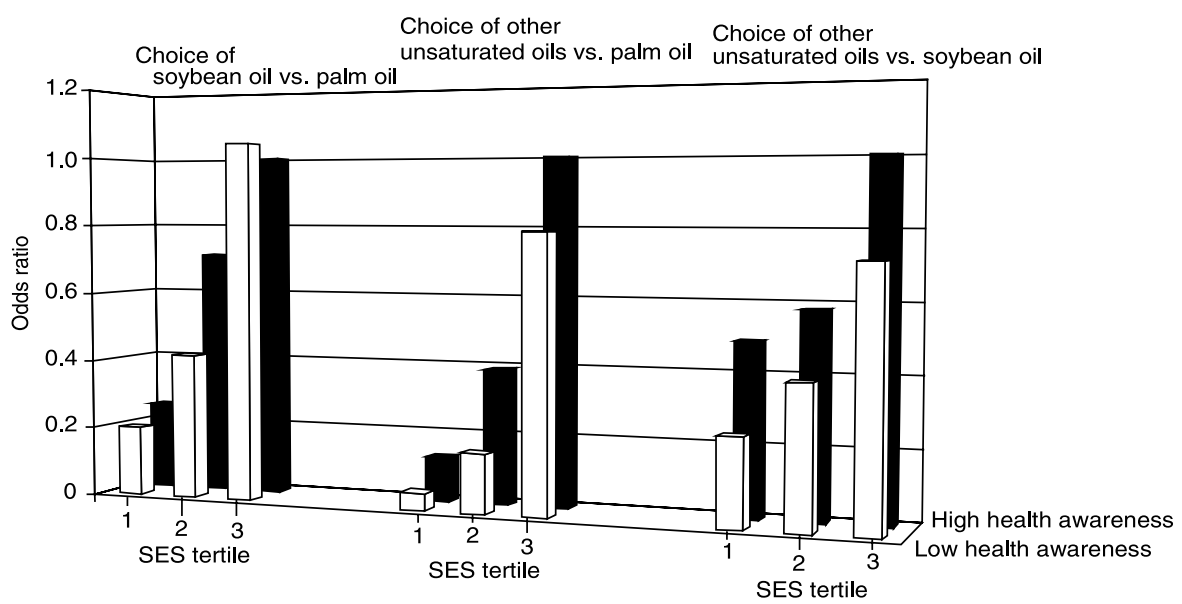

Fig. 2 Interaction between tertiles of socio-economic status (SES) and health awareness as determinants of choice of oil in three models; subjects in the highest SES tertile with high health awareness served as the reference group (test for interaction: $P<0.05$ in all three models). SES was based on quintiles of income, formal education, number of household possessions and occupation; subjects were classified into SES tertiles from lowest (1) to highest (3). Health awareness was based on self-reported history of hypertension and high cholesterol, frequent multivitamin use, non-smoking status and high intake of green leafy vegetables ( $\geq$ median intake of 0.65 servings per day); to score high health awareness, at least three of the five components had to be classified as 'yes'

objectives, it is difficult to obtain all relevant information that would be useful for our purposes and to establish definite trends and changes of behaviour over time, since there are no longitudinal data on the same subject population. More information regarding healthy eating practices and behaviours would have added greatly to the variables that suggest health awareness. It is also difficult to interpret associations regarding gender, since the majority of the sample were male, and since the men and women in our study do not represent couples within a household. Furthermore, information on annual supply would have been helpful: it is well known that palm oil production suffered during 1997-1998 due to El Niño, increasing its demand in some parts of Asia ${ }^{36,37}$; in Costa Rica its prices appear to have remained slightly lower than those for other oils, although we ignore if its supply was altered.

Although foods eaten away from home may be an important contributor to the type of oil consumed in other settings, it does not appear to be the case in this study. In this population only a small percentage (about 5\%) consumed fried foods away from home, and post hoc analyses revealed that among those who frequently consumed foods away from home, the distribution of SES index and of type of oil used in cooking did not vary significantly. This suggests that eating out is not as important a contributor to the type of oil consumed by this population.

Despite these limitations, within the scope of rapidly increasing nutrition-related non-communicable diseases in Costa Rica and other Latin American countries, this study proves to be a timely and valuable investigation on the determinants of the choice of cooking oil in the past decade. With the introduction of new types and brands of oils along with other food products, policies and programmes need to be in place in Costa Rica, as well as other countries undergoing dietary shifts, to ensure the promotion of products with a healthy profile, either by strategies for appropriate nutrition labelling or health education campaigns.

\section{Acknowledgements}

Sources of funding: The study was supported by a predoctoral training grant from the National Institute of Diabetes and Digestive and Kidney Diseases (NIDDK), and grants HL071888 and HL60692 from the National Institutes of Health.

Conflict of interest declaration: The authors have no conflicts of interest.

Authorship responsibilities: U.C.-R. conceived and designed the study, analysed the data and drafted the manuscript. E.K.K. contributed in the design, analyses and presentation of analyses. A.B. collaborated significantly in the interpretation of the data and revisions of the manuscript. A.A., H.C. and K.E.P. shared responsibilities in the conception and design of the study, and interpretation of data analyses. All authors contributed significantly to the presentation of the data and revisions of the manuscript.

Acknowledgements: We would like to thank Dr Rafael Monge-Rojas for his technical assistance, advice and insightful suggestions.

\section{References}

1 Landes R, Westcott P, Wainio J. Oilseeds and products. In: International Agricultural Baseline Projections to 2005. Agricultural Economic Report No. AER750. Washington, DC: US Department of Agriculture Economic Research Service, 1997; 208pp.

2 National Council for Applied Economic Research. Market Information Surveys of Households (1985-1990). 
New Delhi: National Council for Applied Economic Research, 1995.

3 Khor GL. Dietary fat quality: a nutritional epidemiologist's view. Asia Pacific Journal of Clinical Nutrition 2004; 13(Suppl.): S22.

4 Kawachi I, Colditz GA, Ascherio A, Rimm EB, Giovannucci E, Stampfer MJ, et al. A prospective study of social networks in relation to total mortality and cardiovascular disease in men in the USA. Journal of Epidemiology and Community Health 1996; 50(3): 245-51.

5 Katan MB, Zock PL, Mensink RP. Dietary oils, serum lipoproteins, and coronary heart disease. American Journal of Clinical Nutrition 1995; 61(6 Suppl.): 1368S-73S.

6 Lichtenstein AH, Ausman LM, Carrasco W, Jenner JL, Gualtieri LJ, Goldin BR, et al. Effects of canola, corn, and olive oils on fasting and postprandial plasma lipoproteins in humans as part of a National Cholesterol Education Program Step 2 diet. Arteriosclerosis and Thrombosis 1993; 13(10): 1533-42.

7 Klurfeld DM. Tropical oil turmoil. Journal of the American College of Nutrition 1991; 10(6): 575-6.

8 Madrigal S. [Report of National Survey of Food Consumption: Survey of Homes and Multiple Purposes 2001]. San Jose: Ministry of Health Costa Rica, 2001.

9 Araya MR, Padilla SG. [Trends in mortality from ischemic heart disease and acute myocardial infarction in Costa Rica, 1970-2001]. Revista Panamericana de Salud Pública 2004; 16(5): 295-301.

10 Ministry of Health Costa Rica. [Health sector analysis Costa Rica] [online], 2002. Available at http://www.netsalud.sa.cr/ poli0206/index.htm. Accessed April 2006.

11 Popkin BM. The nutrition transition: an overview of world patterns of change. Nutrition Reviews 2004; 62(7 Pt 2): S140-3.

12 Kabagambe EK, Baylin A, Siles X, Campos H. Comparison of dietary intakes of micro- and macronutrients in rural, suburban and urban populations in Costa Rica. Public Health Nutrition 2002; 5(6A): 835-42.

13 Monge-Rojas R, Campos H, Fernandez Rojas X. Saturated and cis- and trans-unsaturated fatty acids intake in rural and urban Costa Rican adolescents. Journal of the American College of Nutrition 2005; 24(4): 286-93.

14 Rodriguez Herrera N, Gladys Arauz A, Meza Rojas N, Rosello Araya M. [Atherogenic factors in the diet of the Costa Rican population, 1991]. Archivos Latinoamericanos de Nutrición 1996; 46(1): 27-32.

15 Hjartaker A, Lund E. Relationship between dietary habits, age, lifestyle, and socio-economic status among adult Norwegian women. The Norwegian Women and Cancer Study. European Journal of Clinical Nutrition 1998; 52(8): 565-72.

16 Mattisson I, Wirfalt E, Gullberg B, Berglund G. Fat intake is more strongly associated with lifestyle factors than with socio-economic characteristics, regardless of energy adjustment approach. European Journal of Clinical Nutrition 2001; 55(6): 452-61.

17 Campos H, Bailey SM, Gussak LS, Siles X, Ordovas JM, Schaefer EJ. Relations of body habitus, fitness level, and cardiovascular risk factors including lipoproteins and apolipoproteins in a rural and urban Costa Rican population. Arteriosclerosis and Thrombosis 1991; 11(4): 1077-88.

18 Campos H, Siles X. Siesta and the risk of coronary heart disease: results from a population-based, case-control study in Costa Rica. International Journal of Epidemiology 2000; 29(3): 429-37.

19 National Institute of Statistics and Census. [Occupation Classification in Costa Rica]. San Jose: National Institute of Statistics and Census, 2000.

20 Expert Committee on the Diagnosis and Classification of Diabetes Mellitus. Report of the expert committee on the diagnosis and classification of diabetes mellitus. Diabetes Care 2003; 26(Suppl. 1): S5-20.

21 Rose GA, Blackburn H, Gillum RF, Prineas RJ. Cardiovascular Survey Methods, 2nd ed. Geneva: World Health Organization, 1982.

22 Kabagambe EK, Baylin A, Allan DA, Siles X, Spiegelman D, Campos H. Application of the method of triads to evaluate the performance of food frequency questionnaires and biomarkers as indicators of long-term dietary intake. American Journal of Epidemiology 2001; 154(12): 1126-35.

23 Campos H, Willett WC, Peterson RM, Siles X, Bailey SM, Wilson PW, et al. Nutrient intake comparisons between Framingham and rural and urban Puriscal, Costa Rica. Associations with lipoproteins, apolipoproteins, and low density lipoprotein particle size. Arteriosclerosis and Thrombosis 1991; 11(4): 1089-99.

24 Baylin A, Siles X, Donovan-Palmer A, Fernandez X, Campos H. Fatty acid composition of Costa Rican foods including trans-fatty acid content. Journal of Food Composition and Analysis 2006 Aug 14; [Epub ahead of print].

25 Meza N, Rodriguez N. [Second National Survey of Apparent Food Consumption 1991]. San Jose: Ministry of Health Costa Rica, Department of Nutrition and Integral Attention, 1993.

26 Office of the Coordinator for Business Affairs, US Department of State. Costa Rica country commercial guide. In: Country Commercial Guides, Electronic Research Collections [online], 1996. Available at http://dosfan.lib.uic.edu/ ERC/economics/commercial_guides/costa_Rica.html. Accessed March 2006.

27 Arauz AG, Monge RA, Munoz L, Rojas MT. [Diet as a risk factor for cardiovascular disease in residents of the metropolitan area, San Jose, Costa Rica]. Archivos Latinoamericanos de Nutrición 1991; 41(3): 350-62.

28 Pollard W. Use of consumer panel survey data for public health communication planning: an evaluation of survey results. In: American Statistical Association 2002 Proceedings of the Section on Health Policy Statistics. Alexandria, VA: American Statistical Association, 2002; 2720-4.

29 Frileux S, Munoz Sastre MT, Mullet E, Sorum PC. The impact of the preventive medical message on intention to change behavior. Patient Education and Counseling 2004; 52(1): 79-88.

30 Blanco A, Viquez N, Paniagua C. [Knowledge and use of prepackaged food labeling in adult consumers of the metropolitan area of Costa Rica]. In: Memory - First Interamerican Congress and VI National Public Health Dr. Daniel Pizarro Torres. Globalization and Health at the Doors of the XXI Century. San Jose: Costa Rican Public Health Association, 1998; 159-61.

31 Hernandez-Grabanzo M, Sibaja-Adams R, Gonzalez-Maroto JR, Blanco-Saenz R. [Analytic foundation for the registry of foods in accordance to risk]. In: Memory - First Interamerican Congress and VI National Public Health Dr. Daniel Pizarro Torres. Globalization and Health at the Doors of the XXI Century. San Jose: Costa Rican Public Health Association, 1998; 149-54.

32 Baylin A, Kabagambe EK, Ascherio A, Spiegelman D, Campos H. High 18:2 trans-fatty acids in adipose tissue are associated with increased risk of nonfatal acute myocardial infarction in Costa Rican adults. Journal of Nutrition 2003; 133(4): 1186-91.

33 Meza N. [Dietetic factors that predispose cardiovascular disease, cancer and osteoporosis in the Costa Rican population]. Masters Thesis, University of Costa Rica, San Jose, 2002.

34 Ewing R, Schmid T, Killingsworth R, Zlot A, Raudenbush S. Relationship between urban sprawl and physical activity, obesity, and morbidity. American Journal of Health Promotion 2003; 18(1): 47-57. 
35 Lindstrom M, Hanson BS, Brunner E, Wirfalt E, Elmstahl S, Mattisson I, et al. Socioeconomic differences in fat intake in a middle-aged population: report from the Malmo Diet and Cancer Study. International Journal of Epidemiology 2000; 29(3): 438-48.

36 US Department of Agriculture, Foreign Agricultural Services. Oilseeds: world market and trades. In: FAS Online Situation and Outlook [online], 2004. Available at http:// www.fas.usda.gov/oilseeds/circular/1998/98-02/toc.htm. Accessed April 2006.

37 Economic and Social Department, Food and Agriculture Organization of the United Nations. Oilseeds, oils and oilmeals. In: Food Outlook - Global Information and Early Warning System [online], February 1998. Available at http:// www.fao.org/documents/show_cdr.asp?url_file=/docrep/ 004/w7867e/w7867e11.htm. Accessed April 2006. 